\title{
Parents' Decision Regarding the Use of Medication Treatment to Control their Children's Hyperactivity
}

\author{
Farrag $S^{1,2 *}$ \\ ${ }^{1}$ Department of Nursing, Umm Al-Qura University, Saudi Arabia \\ ${ }^{2}$ Faculty of Nursing, Mansoura University, Egypt
}

*Corresponding author: Farrag S, Associate Professor at Faculty of Nursing, Umm Al-Qura University, Saudi Arabia

Submission: 漹September 01, 2017; Published: 侮 October 13, 2017

\section{Introduction}

Attention-deficit/hyperactivity disorder (ADHD) is a common neurobiological condition affecting 5-8 percent of school age children. In Saudia Arabia, a study reported that the majority $(83.0 \%)$ of the hyperactive boys were from governmental schools, eighty percent of them were Saudi [1]. In Saudi Arabia there were researches about ADHD, some were related to Prevalence of ADHD in female school children [2], others were related to rates of adherence to pharmacological treatment, Epidemiologic, diagnostic and treatment perspectives [3] while no research explored parents decision making regarding child's medical treatment. Therefore research investigators were interested to study parents' decision making regarding treatment of hyperactivity and the type of treatment received by those children.

ADHD is a treatable condition that could be treated by stimulant medication [4] cognitive behavioral therapy, social skills training, parent education and support, and remedial education. The present study explored factors that influence parent decision-making about the initiation and continuation of treatment. Awareness about these factors may help physicians address the concerns of families while managing hyperactivity.

There are factors that affect parents in their decision making in considering a specific type of treatment for their children with ADHD. Parents of children with ADHD suffer from blaming themselves because of their children's condition. Also, pressure at school put them through many difficulties that may lead to conflicts. They also experience confusions on what treatment their children must take. Because of these reasons, parents experience emotional problems in making the right decision. The decision of starting medications for patients diagnosed with ADHD is usually thought of with the help and support of family members and the belief of parents with regard to biomedical treatment. The failure of other treatments may also make parents decide to start and try new treatment for their children $[5,6]$.

Decisions about medication use for children with ADHD are made and frequently revisited by parents. Choices are often made under stressful conditions and influenced by a variety of factors. Striking a balance between benefits and concerns is an ongoing process that is often informed by contrasting time on and off medication. Development of strategies to support families across the continuum of decisions faced while managing ADHD is warranted [7]. Similar to other pediatric chronic conditions, parents play a key role in implementing treatment plans that are made during visits to the clinic.

The rapidity at which parents accept medication treatment, and the perceptions of medication provide a wealth of information that may help providers better connect with the families and children with ADHD. Parental views may affect therapeutic alliances between parents and pediatric providers, as illustrated in a conceptual model of parental involvement in treatment [8]. Promoting partnerships among parents, teachers, and providers could be easily adopted and applied by nurses in Kingdom of Saudi Arabia (KSA) in order to improve children's lives through a specialized care given by nurses [9].

\section{Significance of the study}

The study is covering a research gap that was not addressed by nursing professionals in Saudia Arabia and in the Middle-East Region. The process of decision making regarding treatment choice did not take enough attention from nursing professionals although they are in a very good position to do so. This aspect will enhance nurses' role in dealing with families and their children with hyperactivity [10].

\section{Aims of the study}

a. Identify factors influencing parents' decision making regarding initiating and continuation of medication treatment for children with hyperactivity.

b. Identify type of treatment used by children with hyperactivity.

Setting: The study was conducted at four primary schools for girls at Makkah and jeddah districts, KSA. 
Subjects and methods: Subjects of the present study (34 parents of school age children) were recruited from primary schools via the help of the school teachers who were dealing with hyperactive children.

\section{Inclusion criteria}

1. Parents who had children with hyperactivity and who were enrolled in the study settings.

2. Parents who decided to take their children to clinic for treatment.

3. Parents who approved to participate in the current study.

Research instrument: Research investigators developed a semi structured questionnaire to identify parents' decision regarding their children's treatment. Adopted types of treatment were also explored using the same tool.

The actual filed work was carried out from 18-12-1433 to 2812-1433H for data collection.

Study design: A descriptive study design was utilized and study subjects were selected via convenient sampling technique.

\section{Research ethics committee approval}

\section{Table 1:}

\begin{tabular}{|c|c|c|}
\hline Factors Contributed to Visiting Physician & No. & $5.88 \%$ \\
\hline Inappropriate appointment & 2 & $5.88 \%$ \\
\hline Long distance & 2 & $11.76 \%$ \\
\hline Difficult transportation & 4 & $14.70 \%$ \\
\hline Less awareness of fathers & 5 & $11.76 \%$ \\
\hline Fear from medical diagnosis & 4 & $5.88 \%$ \\
\hline Fear from addiction & 2 & $5.88 \%$ \\
\hline Lack of time to visit the clinic & 2 & $5.88 \%$ \\
\hline Difficult to access the service & 2 & $20.58 \%$ \\
\hline Mental health stigma & 7 & $5.88 \%$ \\
\hline Don't know & 2 & $5.88 \%$ \\
\hline Socio-economic reasons & 2 & $100 \%$ \\
\hline Total & 34 & \\
\hline
\end{tabular}

\section{Table 2:}

\begin{tabular}{|c|c|c|c|c|c|}
\hline & \multirow{3}{*}{ Items } & \multicolumn{4}{|c|}{ Parents' Decision Making to Visiting Doctor } \\
\hline & & \multicolumn{2}{|c|}{ Yes } & \multicolumn{2}{|c|}{ No } \\
\hline & & No. & $\%$ & No. & $\%$ \\
\hline \multirow{3}{*}{$\begin{array}{l}\text { family size of children with } \\
\text { hyperactivity }\end{array}$} & Large Family (5-20) members & 16 & $47.05 \%$ & 4 & $11.76 \%$ \\
\hline & Average size Family (3-4) members & 6 & $17.64 \%$ & 4 & $11.76 \%$ \\
\hline & Small Family (1-2) members & 1 & $2.90 \%$ & 3 & $8.82 \%$ \\
\hline \multirow{2}{*}{$\begin{array}{c}\text { Parent's Knowledge about } \\
\text { Hyperactivity }\end{array}$} & Yes & 17 & $50 \%$ & 2 & $5.88 \%$ \\
\hline & No & 5 & $14.70 \%$ & 10 & $29.41 \%$ \\
\hline \multirow{3}{*}{ Place of residence } & Jeddah & 14 & $41.17 \%$ & 2 & $5.88 \%$ \\
\hline & Makkah & 9 & $26.47 \%$ & 9 & $26.47 \%$ \\
\hline & Total & 34 & $100 \%$ & 34 & $100 \%$ \\
\hline
\end{tabular}


Table 2 shows that more than two-thirds of the study sample was exposed to medical assessment and evaluation as evidenced by their parents' reports. Also the table demonstrated that (18.2\%) of parents who did not receive medication because of fear from addiction, while very little percent disapproved it due to fear of side effects in general. Another parent did not believe in medication at all. Also that three-quarter $(69.5 \%)$ of the treated children were treated by drug therapy only while quarter of them treated by both behavior and medication therapy only. And more than half (58.8\%) of parents received information about treatment by doctor [11]

\section{Conclusion}

Since the researches explored the factors that could be contributing to parents' decision regarding child's treatment, the study concluded that one third of the parents (medication group) were concerned about visiting the Mental Health Clinic due to fear of stigma. Some parents were worried about the medical diagnosis, while others were having difficulties in accessing the Mental Health Service due to various reasons such as (in appropriate appointment, difficult transportation, cost of the visit, and the lack of awareness of fathers). Saudi culture was one of the major issues that contributed to parent's decision making as many of them did not believe in the value of medication. Regarding to the type of treatment received by children with hyperactivity, it was found that nearly $(70 \%)$ parents decided to give their children the medication while less than $(26 \%)$ of them decided to provide their children with combined treatment (medication plus behavioral therapy). These decisions were taken after visiting Child Mental Health Clinic (CMHC) either in governmental (39\%) or in private clinics $(61 \%)$ for a number of times. Nursing professionals are therefore in very good position to enhance parent's decision at the stages of (prediagnosis, and post - diagnosis) of their children's condition. They can also play a vital role in selecting the type of treatment that is appropriate for their children [12].

\section{Recommendations}

\section{Recommendations for school nurses}

A. School nurses should conduct educational programs should be concluded for school professionals on child Mental Health Problems, in order to early discover these cases.

B. Training program to school nurse support for parents whose children are suffering from hyperactivity.

\section{Recommendations for mothers}

a) Nurse could educate parents on medication compliance to improve the child's health outcome.

b) Pediatric nurses should be able to train mothers on some social skills that would in directly improve their children's response to treatment.

\section{Recommendations for school administration}

I. School administration must follow the guiding children through school health condition of the child.

II. School administration must establish educational health programs for mothers and health supervisors about hyperactivity

\section{Recommendations for teachers}

1. School should monitor children diagnosed overheating and concern for them and deal with them a gentle manner.

2. Parameter should monitor behavior in the case of the emergence of any strange behavior must be reported to health honorable to call the mother and tell her the situation of her child children's.

\section{Study limitations}

1. Randomization was not possible due to practical difficulties and ethical reasons.

2. The sample size was small, due to the time limitation of the data collection of the study.

\section{References}

1. Al Hamed JH, Taha AZ, Sabra AA, Bella H (2008) Attention Deficit Hyperactivity Disorder (ADHD): Is it a Health Problem among Male Primary School Children. Bahrain Medical Bulletin 30(2).

2. Jenahi E, Khalil MS, Bella H (2012) Prevalence of attention deficit hyperactivity symptoms in female schoolchildren in Saudi Arabia. Ann Saudi Med 32(5): 462-468.

3. Al Ghamdi YS, Omer MI, Khalil MK, Ali SA, Barmada RA, et al. (2002) Clinical evaluation of disabled children in Al-Qassim region, Saudi Arabia. Neurosciences (Riyadh) 7(4): 272-277.

4. Williams DE (2008) What causes ADHD? Some intriguing findings.

5. J Amer Academy of Child and Adolescent Psychiatry (2010) Your Child Attention-Deficit/Hyperactivity Disorder from.

6. Wilens TE (2002) New Advances in the Psychopharmacological Treatment of Attention-Deficit/Hyperactivity Disorder. J Amer Academy of Child and Adolescent Psychiatry.

7. Brinkman WB, Sherman SN, Zmitrovich AR, Visscher MO, Crosby LE, et al. (2009) Parental Angst Making and Revisiting Decisions About Treatment of Attention-Deficit/Hyperactivity Disorder. Pediatrics 124(2): 580-589.

8. DosReis S, Myers MA (2008) Parental attitudes and involvement in psychopharmacological treatment for ADHD: A conceptual model. Int Rev Psychiatry 20(2): 135-141.

9. McGuinness TM (2008) Helping parents decide on ADHD treatment for their children. J Psychosoc Nurs Ment Health Serv 46(8): 23-27.

10. Barkley RA, Edelbrock CS (1987) Assessing situational variation in children's behavior problems: The Home and School Situations Questionnaires. In: Prinz R (Ed.), Advances in behavioral assessment of children and families, JAI Press, Greenwich, 3: pp. 157-176.

11. Elyssa Finkel (2011) Parental income, Education and the Diagnosis of ADHD in children and Adolescents. Centre for European Economic Research 120(2): 242-211.

12. Barkley RA, Fischer M, Edelbrock CS, Smallish L (1990) The adolescent outcome of hyperactive children diagnosed by research criteria: I. An 8 year prospective follow-up study. J Am Acad Child Adolesc Psychiatry 29(4): 546-557. 